\title{
LUGAR QUE A ESCOLA OCUPA PARA ALUNOS DO ENSINO FUNDAMENTAL: Motivos para sua Permanência nesse Espaço
}

\author{
Mônica Tessaro ${ }^{1}$ \\ Maria Teresa Ceron Trevisol ${ }^{2}$ \\ Luci dos Santos Bernardi ${ }^{3}$
}

\begin{abstract}
RESUMO
Analisando o contexto da modernidade líquida, é possível observar que a escola vem recebendo um grupo de alunos cada vez mais heterogêneo, caracterizado pelas diversidades sociais, culturais, econômicas, políticas, étnicas e de gênero. É nesse local, marcado por diferenças, que os jovens passam parte de seu tempo, estabelecem laços afetivos e compartilham experiências, concebendo motivos por permanecerem ali. Considerando que a educação é destacada, por muitos jovens, como um meio para ultrapassar as fronteiras sociais e econômicas, objetiva-se, com este artigo, analisar os motivos atribuídos por alunos que frequentam o Ensino Fundamental para sua permanência na escola. $\mathrm{O}$ artigo possui, como base empírica, uma pesquisa de abordagem qualitativa. A coleta dos dados ocorreu por meio da técnica do Grupo Focal, e na análise utilizou-se a metodologia da Análise Textual Discursiva. Os dados revelaram que os principais incentivos listados pelos jovens sobre a permanência na escola são os bons professores e os pais.
\end{abstract}

Palavras-chave: Motivos de permanência na escola. Alunos do Ensino Fundamental. Jovens. Modernidade líquida.

THE PLACE THAT SCHOOL OCCUPIES FOR ELEMENTARY SCHOOL STUDENTS:

REASONS FOR THEIR PERMANENCE IN THIS SPACE

\begin{abstract}
RECEBIDO EM: 25/4/2020

ACEITO EM: $16 / 6 / 2020$
\end{abstract}

Analyzing the context of liquid modernity, it is possible to observe that the school has been receiving an increasingly heterogeneous group of students, characterized by social, cultural, economic, political, ethnic and gender diversity. It is in this place marked by differences that young people spend part of their time, establish emotional bonds and share experiences, giving reasons for staying there. Considering that education is highlighted by many young people as a mean to overcome social boundaries, the aim of this article is to analyze the reasons, attributed by students who attend elementary school, for their permanence in school. The article is based on empirical research with a qualitative approach. Data collection took place using the Focus Group technique, and the analysis used the Discursive Textual Analysis methodology. The data revealed that the main incentives listed by young people about staying in school are good teachers and parents.

Keywords: Reasons for staying in school. Elementary school students. Young. Liquid modernity.

\footnotetext{
1 Autora correspondente. Universidade do Oeste de Santa Catarina - Unoesc. Joaçaba/SC, Brasil. http://lattes.cnpq.br/8615322102698889. https://orcid.org/0000-0003-4784-3606.m_tessaro@unochapeco.edu.br

2 Universidade do Oeste de Santa Catarina - Unoesc. Joaçaba/SC; Chapecó/SC, Brasil.

3 Universidade Regional Integrada do Alto Uruguai e das Missões - URI/FW. Frederico Westphalen/RS, Brasil.
} 
Em uma pesquisa realizada por Souza (1997) sobre as taxas de escolarização da população brasileira, a autora destacou a presença de um ensino de primeiro grau altamente seletivo, no qual apenas $27 \%$ das crianças que ingressavam na escola concluíam o primeiro grau no Brasil. De acordo com Abramovay (2015), diferentes pesquisas têm advogado a favor das políticas preventivas à evasão escolar, sobretudo com a intenção de melhor compreender os desconfortos em relação à educação, no entanto poucos estudos investigam as razões consideradas atrativas para que os alunos prossigam sua trajetória acadêmica. Ao acessarmos os dados apurados pelo Censo Demográfico divulgados pelo Instituto Brasileiro de Geografia e Estatística (IBGE), em 2013 o número de crianças e jovens de zero a 24 anos correspondia a 40,6\% da população brasileira, e a maior concentração dessa população estava inserida nos anos iniciais do Ensino Fundamental. Dos jovens brasileiros, no entanto, 54\% dos que tinham 15 anos de idade e $80,9 \%$ dos que tinham 19, ainda não haviam concluído o Ensino Fundamental, posto que a idade estipulada para os alunos do Ensino Fundamental é de 6 a 14 anos (BRASIL, 2013).

Quatro anos depois desse levantamento, o Instituto Nacional de Estudos e Pesquisas Educacionais Anísio Teixeira (Inep) divulga a seguinte manchete: "Mais da metade dos adultos brasileiros não chegam ao ensino médio"; essa afirmação se deu a partir de uma pesquisa realizada em 2015, no entanto sua divulgação ocorreu em 2017. Nesse período, mais da metade dos adultos, entre 25 e 64 anos, não tinha acesso ao Ensino Médio, e $17 \%$ da população sequer havia concluído o ensino básico. De acordo com os dados divulgados pelo Inep, 7,7\% dos alunos matriculados no 9o ano do Ensino Fundamental evadiram da escola, seguidos pela 3ạ série do Ensino Médio, com 6,8\%. Considerando todas as séries do Ensino Médio, a evasão chega a 11,2\% do total de alunos nessa etapa de ensino (INEP, 2017).

Partindo desse cenário, se considerarmos o número de alunos que mantêm seus nomes na lista de matrícula e não comparecem regularmente às aulas, tendo com a escola uma relação dolorosa, falha e, na maioria das vezes, frustrante, reconhecemos que no Ensino Fundamental esses índices são maiores. Um dos motivos da evasão escolar, destacado por Gomes e Souza (2009, p. 41), refere-se às "práticas pedagógicas que não contemplem, efetivamente, a diversidade." Dessa forma, consideramos que boa parte desses adolescentes não concluiu o Ensino Fundamental em virtude de consequências internas e externas, tanto as motivadas pelo alto índice de repetência e fragilidade formativa dos docentes quanto pelas inadequações da estrutura física dos prédios escolares ou pelos currículos, que destoam da realidade vivenciada pelos adolescentes (CAIERÃO, 2008; ABRAMOVAY, 2015).

Presenciamos, ao longo do século 20, questionamentos e debates a respeito do papel que a escola ocupa na vida de crianças e jovens. O modelo tradicional, baseado nos ideais positivistas, inaugurado no século 19, parece não fazer mais sentido aos alunos, principalmente aos "nascidos em tempos líquidos" (BAUMAN; LEONCINI, 2018). Estudos sobre a juventude na contemporaneidade estão crescendo cada vez mais, e neles se discute a necessidade de reconhecer o jovem como sujeito de direitos que influencia e é influenciado pelas mudanças sociais e históricas que ocorreram e vêm ocorrendo na sociedade. Para Velho (2006, p. 194), não existe uma maneira de ser jovem, “[...] basta 
pensar nas nebulosas entre infância e adolescência, adolescência e juventude, juventude e maturidade, maturidade e velhice. Todas essas categorias e sua duração são discutíveis e sujeitas a constantes revisões, redefinições e reinterpretações."

Por isso, os autores que versam a respeito do tema estão preocupados em desmistificar as classificações pela faixa etária dos indivíduos (NOVAES, 2006; VELHO, 2006). A juventude contemporânea é caracterizada por diferentes movimentos, a música, a mídia, os esportes, a família, o consumo, os amigos, dentre outros que oportunizam ao jovem a elaboração de seus projetos e o desenvolvimento de suas trajetórias sociais.

As definições acerca do que é ser jovem têm mudado com o passar do tempo, sendo desiguais nos diferentes contextos sociais. Por exemplo, "[...] aos que não têm direito à infância, a juventude começa mais cedo. E no outro extremo, com aumento de expectativas de vida e as mudanças no mercado de trabalho, uma parte deles acaba por alargar o chamado tempo da juventude até a casa dos 30 anos." (NOVAES, 2006, p. 106). Como consequência, jovens com a mesma faixa etária vivem juventudes desiguais; basta olharmos os índices de acesso e permanência das escolas brasileiras (BRASIL, 2013; INEP, 2017).

Considerando essas contribuições, destacamos, ainda, que o presente estudo é um excerto da dissertação intitulada Jovens olhares sobre a escola: vivências dos processos educativos a partir do background e do foreground (TESSARO, 2018), posto que a motivação deste artigo ocorreu a partir do objetivo de analisar os motivos atribuídos por alunos que frequentam o Ensino Fundamental para sua permanência na escola.

O texto que segue, portanto, está organizado em seções: na primeira apresentamos o cenário da pesquisa e os procedimentos metodológicos. Na sequência, é exposta a análise dos dados que está representada pela categoria "Os jovens como seres viáveis", a qual contempla as seguintes unidades de sentido: i) atitudes dos jovens na escola; ii) sobre continuar os estudos; e iii) os principais motivos para continuarem na escola. Por meio dessas unidades de sentido, oportunizamos aos participantes o exercício autorreflexivo sobre seus comportamentos, bem como apresentamos os motivos atribuídos pelos alunos participantes da pesquisa em relação à sua permanência na escola. Por fim, tecemos as considerações finais e elencamos as referências bibliográficas empregadas na pesquisa.

\section{O CENÁRIO DA PESQUISA}

O estudo foi realizado com um grupo de nove adolescentes, com idades dos 14 aos 17 anos, que estavam matriculados em 2017 no 9o ano do Ensino Fundamental em uma escola pública, localizada em um bairro periférico do oeste catarinense. Os critérios de participação na pesquisa, foram: a) estar matriculado no 9o ano e ter frequência acima de $75 \%$ nas aulas; b) garantir a participação de meninos e meninas; e c) manter frequência nos quatro encontros do grupo focal. Após aprovação do projeto de pesquisa pelo Comitê de Ética e Pesquisa, nos deslocamos até à escola selecionada em que efetuaríamos a investigação. A direção possibilitou-nos o contato com a turma do 9 ㅇ ano, a qual era composta por 14 estudantes. Ao explanarmos os objetivos da pesquisa, nove alunos aceitaram colaborar, sendo cinco do sexo feminino e quatro do sexo 
masculino. Optamos pelos alunos do 90 ano tendo em vista os indicadores estatísticos (BRASIL, 2013; INEP, 2017), que têm apresentado que é nessa fase da escolarização que ocorre, de forma mais acentuada, a saída dos alunos da escola.

Por se tratar de uma pesquisa qualitativa, utilizamos para a coleta de dados as técnicas do grupo focal, e, ao todo, foram realizados quatro encontros com os adolescentes, com duração de 50 minutos cada, os quais ocorreram em horário de aula em uma sala isolada da escola, ou seja, somente os participantes da pesquisa tinham acesso à sala, preservando o sigilo e os aspectos éticos na pesquisa. Vale destacar que os encontros ocorreram durante o horário de aula dos participantes, pois trabalhavam no contraturno escolar, inviabilizando a participação na pesquisa. As técnicas do grupo focal ocorreram a partir da interação entre os participantes e a pesquisadora (a primeira autora deste estudo), tendo por objetivo coletar informações por meio de discussões focadas em tópicos específicos. A principal característica dessa técnica é seu caráter interativo salientado as trocas entre os componentes do grupo. Esses aspectos permitem diferenciar a técnica do grupo focal pelo seu potencial de produção de informações, que somente é permitido por meio do diálogo que ocorre entre os participantes do mesmo grupo (MEYER; PARAÍSO, 2014).

Todos os encontros foram filmados, e, após cada um, todo o material coletado foi transcrito, lido e analisado. Na primeira etapa de análise os primeiros passos foram na tentativa de fragmentar e/ou desmontar os diálogos gravados no grupo, no sentido de atingir unidades constituintes referentes às questões estudadas e, a partir disso, chegar às unidades de sentido. Construídas as unidades de sentido, o passo seguinte foi a elaboração das relações entre elas, classificando-as em elementos unitários no sentido de compreender como poderiam ser reunidas na formação de conjuntos mais complexos, chegando às categorias emergentes.

A característica desse processo foi configurada por meio da Análise Textual Discursiva (ATD), apresentada por Moraes e Galiazzi (2016), como uma metodologia qualitativa para a análise de dados que objetiva produzir novas compreensões sobre fenômenos e discursos. A partir dessa metodologia de análise, os dados foram organizados em quatro categorias emergentes; cada categoria abarcou outras três unidades de sentido, as quais consideraram os aspectos mais relevantes presentes nos discursos dos alunos. Destacamos que, neste artigo, apresentaremos apenas as análises da categoria "Os jovens como seres viáveis e educáveis", com suas respectivas unidades de sentido. No artigo, "a fala", os posicionamentos dos jovens, estão destacados em itálico, seguidos da abreviatura dos nomes e a idade dos participantes.

\section{OS JOVENS COMO SERES VIÁVEIS E EDUCÁVEIS}

Sou tudo, menos desesperançoso. Confio na perseverança dos jovens

(BAUMAN, 2013, p. 35).

Entre os destaques deste estudo, apontamos para os encantos dos jovens em relação à escola, sem deixar de destacar as fragilidades e problemas do cotidiano escolar, entre eles as limitações, inclusive, de horizonte crítico sobre educação e conhecimento 
de uma população jovem e de baixa renda, sem rotular os adolescentes a partir dos estigmas contemporâneos, mas vê-los, sobretudo, como sujeitos de desejo e, além disso, acreditar, mesmo nesses tempos marcados pelos processos de desumanização a que estamos submetidos e aos quais o "ser humano é viável". Os adolescentes e jovens, em geral, enquanto categoria social, encontram-se desacreditados. Não precisamos ir muito longe para ver ou ouvir descrenças a respeito da viabilidade e da educabilidade dos jovens (ARROYO, 2015).

Para Arroyo (2015), a pedagogia nasceu acreditando na viabilidade do ser humano. Essa crença mobilizou as esferas políticas, tornando a educação direito de todos e dever do Estado, no entanto, com a chegada da liquidez, enfrentamos uma crise a esse respeito. Arroyo (2015) parte da hipótese de que vivenciamos a descrença na docência, porque nos invade a descrença no jovem pobre, negro e morador dos bairros periféricos que acessam a escola. A sociedade contemporânea vivencia a segregação dos jovens e até mesmo das crianças, encarando-os como violentos, ineducáveis, desejando entregá-los à justiça penal, pois os entende como humanos inviáveis.

Nesse sentido, a escola, considerada um espaço promotor de encontros, amizades, socializações, em muitas situações promove desencontros, angústias e exclusão em razão das suas balizas disciplinares. Corroboramos as palavras de Melo e Salles (2020, p. 88), quando referem que "tal processo, porém, não é intencional e visível aos próprios alunos, pois, quando indagados sobre suas perspectivas de futuro, remetem à necessidade do Ensino Superior e da obtenção de um diploma escolar." Os professores surpreendem-se com o comportamento dos jovens, e os veem como se viessem de outro mundo, e, para garantir a ordem, logo os encaixam em suas tradicionais polarizações: os fortes e os fracos, os bons e os ruins, os que obterão sucesso e os que fracassarão. De acordo com Arroyo (2015), essas polarizações não apontam qualquer final feliz, e, pior, os jovens parecem estar submetidos às vidas desperdiçadas (BAUMAN, 2013).

O papel atribuído pelos jovens à educação em relação ao futuro e à centralidade estratégica dos professores e dos pais, ganha destaque neste trabalho e aflora espontaneamente nos discursos da escola, que contribuem com as perspectivas de futuro, vetor que alimenta o desejo de permanecerem nesta instituição. Por isso, nesta categoria, nosso objetivo foi demonstrar, a partir das falas dos próprios alunos, que a educação é considerada por eles a chave do sucesso, uma vez que reconhecem seus comportamentos reprováveis, mas têm nos pais e nos bons professores a inspiração que precisam para permanecerem na escola, procurando, portanto, melhores condições de vida por meio da educação.

\section{ATITUDE DOS JOVENS NA ESCOLA}

Se lêssemos mais, estudássemos mais, acho que seria mais fácil de aprender (A. P., 15 anos).

Se as escolas estimulassem o gosto pela leitura e pela escrita, haveria um número menor de jovens falando sobre sua insegurança ou sua incapacidade de aprender. Se estudar não se caracterizasse um fardo, se ler não se configurasse uma amarga obrigação, teríamos melhores índices sobre nossa educação (FREIRE, 2015). 
Os adolescentes não nasceram com problemas de comportamento, no entanto suas vivências podem ser marcadas por complexos processos de socialização que acabam resultando em comportamentos indesejados pela instituição escolar. Por outro lado, os adolescentes carregam a sensação de estar sendo vigiados o tempo todo, agora não mais pelo olhar dos professores, mas, sobretudo, por eles próprios, e acabam legitimando e validando seus comportamentos considerados inadequados: "Às vezes passamos dos limites durante as aulas" (I. S., 16 anos).

Nesse sentido, é possível perceber que os jovens já abarcaram o processo individualizante da modernidade líquida, assumindo seus comportamentos inadequados. Aquilo que antes era poder do panóptico, na modernidade líquida instalou-se nos próprios indivíduos, como o sentimento de constante vigilância e, principalmente, de autovigilância. Foi Bauman (2001) quem lançou a ideia de pós-panóptico ou vigilância líquida, explicando o sentimento de estar sendo autovigiado. Atualmente não existe mais um olhar centralizador com o poder de vigiar; os pontos de vigilância estão flutuando a cada movimento, e cada indivíduo deixa-se vigiar por conta própria.

Na proposta de Bauman (2013) já não existe uma referência arquitetônica como um centro de vigilância; surgiram novos dispositivos que têm a capacidade de gravar, fotografar e filmar tudo em tempo real, sendo armazenados e compartilhados por muitos. Dessa forma, há uma constante impressão de estar sendo vigiado sem se dar conta que o principal facilitador disso tudo é o ser humano, ou seja, Bauman (2013) analisa que o próprio estudante já se automonitora.

Enganam-se, no entanto, os que pensam que apenas reconhecendo seus comportamentos são socialmente aceitos. No contexto da modernidade líquida, para ter acesso aos comportamentos dos outros basta um clik nas redes sociais, e, a partir disso, sempre terá alguém pronto para criticar, reacendendo a reflexão coletiva sobre a moral e a ética que envolvem tal fenômeno: "Porém, mesmo quando as aulas são boas tem gente que não se interessa, que não presta atenção, que não participa" (A. T. R., 17 anos). Os jovens reconhecem, em suas falas, que acabam se prejudicando em razão das brincadeiras, mas apontam uma razão para isso: "A gozação acaba sendo mais atrativa que muitas aulas" (M. B., 15 anos).

Denunciam, nessas falas, que algo não está indo bem e, como consequência, apresentam comportamentos perversos na escola. De acordo com Piaget (1998), comportar-se desse modo pode indicar uma má-adaptação ao sistema de ensino, ou, ainda, uma nova forma de poder que vem se infiltrando nas escolas. $O$ autor continua afirmando que a insituição escolar deve se preocupar mais com a formação da moral dos seus alunos e menos em moldar seus comportamentos consoantes aos fixados na modernidade. Evidenciou-se em nosso estudo, no entanto, que a liberdade da modernidade líquida tem causado um estilo de comportamento reprovável, inclusive entre os próprios jovens.

Esse tipo de comportamento também foi evidenciado em uma pesquisa realizada por Abramovay (2015), a qual envolveu 8.283 jovens estudantes do Ensino Médio das Regiões Norte, Nordeste, Sul, Sudeste e Centro-Oeste brasileiras. Os participantes tecem, igualmente, críticas aos próprios colegas em consequência de algumas características e comportamentos. Assim, a saída sugerida pelos pesquisados foi: "mudar alguns 
alunos da escola; tirar os alunos bagunceiros e os que não querem estudar da sala [...] na linha de medidas individualizadas contra colegas, alguns alunos chegam a reivindicar punições severas com objetivo de diminuir a indisciplina em sala de aula" (ABRAMOVAY, 2015 , p. 223). De fato, radicaliza-se, propondo que os alunos bagunceiros sejam transferidos de escola ou separados em outras salas.

Essa postura individualizante e culpabilizante, de acordo com Bauman (2013), é típica da modernidade líquida. Pensar em alternativas pedagógicas dessas relações tornou-se um desafio na modernidade líquida, pois envolve toda comunidade escolar, uma vez que, de acordo com Nogaro e Pacheco (2019, p. 133), "propor que as relações entre as pessoas sejam pautadas pelo pedagógico significa imaginá-las como horizonte de construção de outras relações humanas, que se contraponham àquelas encontradas na sociedade líquida."

Perante as afirmações trazidas pelos jovens, é possível constatar que a educação enfrenta uma crise, e a falta de qualidade nas relações sociais aponta aspectos negativos da escola. Nussbaum (2015) destaca que o ocidente tem desenrolado uma crise silenciosa nas instituições escolares, minando as possibilidades de desenvolvimento de laços fraternos. Na sociedade líquida continuam a ensinar os jovens sem refletir sobre os processos de humanização; ensinam para obter lucro, competirem entre si; "se tal tendência continuar, as nações em todo o mundo estarão produzindo gerações de máquinas úteis, e não cidadãos, [...] que possam pensar por si e pelos outros" (NUSSBAUM, 2015, p. 5).

\section{SOBRE CONTINUAR OS ESTUDOS}

Eu não quero parar de estudar, mesmo que reprovar vou continuar; eu quero ter uma vida melhor

(B. M., 14 anos).

Oito dos nove adolescentes participantes da pesquisa desejam prosseguir os estudos. Reconhecemos que esses dados estão na contramão do sentimento pessimista que estamos vivenciando na contemporaneidade; isso porque inquiridos sobre os motivos de permanecerem na escola, os adolescentes participantes desta investigação posicionaram-se de forma positiva, ou seja, manifestaram o desejo de permanência. A justificativa dada é ter uma vida melhor (B. M., 14 anos) e, dessa forma, parecem encarar os estudos como uma oportunidade de avanço, novas conquistas e melhoramento do capital cultural. De fato, a educação é vista por muitos jovens, das classes menos favorecidas, como uma maneira de atravessar a fronteira social e econômica. Em seu lado da fronteira, os adolescentes participantes desta pesquisa ocupam postos de trabalho mal remunerados, que exigem esforço físico, e parte de seus salários é destinada a ajudar nas despesas de casa. Sonham, portanto, em ter uma vida melhor, e a educação é, para eles, um caminho.

Em consonância com os nossos resultados, destacamos uma pesquisa realizada por Abramovay e Castro (2003), em âmbito nacional, em que participaram mais de 50 mil alunos, na qual os autores elucidaram que os jovens que apostam na possibilidade de mudança não desistem da escola. Os jovens acreditam conquistar novos caminhos 
por meio da educação, com mais oportunidades e melhores condições. Destacamos, ainda, uma pesquisa realizada por Franco e Novaes (2001, p. 178), que entrevistaram 481 jovens estudantes do Ensino Médio do Estado de São Paulo com o objetivo de investigar as representações sociais a respeito da escola e do prosseguimento dos estudos. Na investigação houve a constatação que "em $50 \%$ dos casos, há a crença de que a escola possibilitará melhores oportunidades do jovem ser alguém na vida ou de ingressar no mercado de trabalho."

Em linha com essas observações, destacamos outra pesquisa realizada por Franco (2002, p. 200), na qual participaram cerca de 700 alunos que cursavam o Ensino Fundamental no Estado de São Paulo. Quando indagados sobre o motivo pelo qual frequentavam a escola, 64,7\% afirmaram que "é para ser alguém na vida; para ter um futuro melhor, em geral vinculado ao mercado de trabalho e ao acesso ao ensino superior" (FRANCO, 2002, p. 201).

Falas como essas indicam a dupla expectativa que o aluno desenvolve em relação ao seu prosseguimento aos estudos. Ou seja, quer cursar o ensino médio, para poder ter acesso ao ensino superior. Ao mesmo tempo, almeja, no bojo da escolarização de nível médio, a credencial de uma profissão, o que a curto ou a médio prazos, vai lhe proporcionar um posto melhor remunerado no mercado de trabalho (FRANCO, 2002, p. 198).

É de conhecimento de todos que as escolas têm deixado a desejar no que diz respeito à formação integral das crianças e jovens (CAIERÃO, 2008), no entanto essa não é uma lacuna apenas do ensino público, pois muitas escolas privadas são igualmente questionáveis no que se refere à excelência do ensino que ofertam. Dessa forma, o que gostaríamos de destacar é que, bem ou mal, a escola presente na contemporaneidade está sendo considerada importante, principalmente pelas camadas menos privilegiadas (FRANCO; NOVAES, 2001).

O papel atribuído hoje à educação tem-na colocado no patamar de promotora de crescimento econômico e social. Ainda, segundo Franco e Novaes (2001, p. 179), "passados os tempos da exaltação da teoria do capital humano, convive-se atualmente com sua retomada, acrescida, agora, de elementos compatíveis com uma visão de modernidade e de globalização."

Concordamos que a escola deve preparar os alunos para enfrentar os desafios da contemporaneidade, mas essa não é tarefa fácil, sobretudo quando a escola é vista como a única possibilidade de ser alguém na vida (M. B., 15 anos). Diante dos dados analisados, os adolescentes deixam claro o desejo de realização profissional, associado à continuação dos estudos: "eu quero ter um emprego melhor, mas para isso tenho que fazer uma faculdade" (A. T. S., 16 anos). O desejo de continuar os estudos está incorporado nos discursos dos adolescentes que participaram do grupo focal, no entanto, ao afirmar desejarem cursar o Ensino Superior, os participantes apontam as dificuldades financeiras para ingressar e, sobretudo, para se manterem na universidade: "sei que não vai ser fácil fazer faculdade, pois custa caro" (A. L., 14 anos).

Acreditamos que esse é um dos limites da instituição escolar, uma vez que a educação, por si só, não promove ascensão social (FREIRE, 2015). Por esse motivo, "cabe, pois, explicitar junto aos alunos os inúmeros obstáculos contextuais e conjunturais que, 
concretamente, dificultam o alcance de determinadas metas e de alguns objetivos específicos" (FRANCO; NOVAES, 2001, p. 180); metas e objetivos que, em nossa pesquisa, encontram-se associados ao desejo de querer ser alguém na vida (M. B., 15 anos).

São esses alunos (os mais carentes e menos preparados) que concorrerão, supostamente em condição de igualdade, com outros (que possuem melhores condições econômicas e sociais) "a um posto, um cargo, uma ocupação no mercado de trabalho, ou irão disputar, com seus pares, a tão almejada possibilidade de continuar os estudos, e quem sabe, ingressar no ensino superior" (FRANCO, 2002, p. 203). Nesse cenário, de acordo com Porcheddu (2009, p. 674), "é fácil sentir-se perdido e sem esperança", ainda mais para quem é impedido de alcançar seus sonhos em razão das limitações econômicas da globalização.

Confiar os esforços pessoais em prol da imposição e do desenvolvimento de si mesmo a visões essencialmente imprevisíveis - e assim declaradamente pouco confiáveis - das exigências futuras do mercado mutável e caótico, faz pressagiar um grande sofrimento humano associado à frustração, esperanças vãs e vida desperdiçada [...] (PORCHEDDU, 2009, p. 677).

Bauman (2013) nos alerta-nos sobre o perigo da individualização. O autor chama aqueles que não conseguem se colocar no mercado de "consumidores excluídos"; o estigma que ninguém quer ter é o de uma vida sem realizações, de não ser reconhecido como pessoa, de não servir para nada. Na contemporaneidade, a completude do ser humano parece estar atrelada ao comprar. Bauman (2013, p. 83) usa o seguinte slogan: "compro, logo existo [...], comprar, significa ter dignidade humana", do contrário, denota não somente falta de prazer, mas de dignidade, de significado na vida. Sob as lentes de Bauman (2013), portanto, o próprio comportamento dos jovens, ao se preocuparem com os estudos, pode estar associado ao desejo de se manterem incluídos na sociedade de consumo na qual vivemos.

\section{OS PRINCIPAIS MOTIVOS PARA CONTINUAREM NA ESCOLA}

Se tivermos incentivo dos pais nós conseguimos dar conta; com incentivo deles parece que tudo fica mais fácil (H. N. R., 16 anos).

A escola parece assumir um lugar de destaque na escala valorativa da família, por conta de ampliar os horizontes de futuro no sentido de os jovens serem alguém na vida. Em uma investigação realizada com jovens do Ensino Médio, constatou-se a importância dos pais como incentivadores na continuação dos estudos. Quando Dayrell e Jesus (2016, p. 412) questionaram os estudantes "sobre como as famílias lidavam com a situação escolar, os depoimentos dos jovens [...] foram unânimes em reconhecer que a família se coloca, quase sempre, a favor da continuidade dos estudos."

Nesse sentido, frequentar uma instituição escolar coloca-se como um investimento para o futuro, mas, de acordo com Dayrell e Jesus (2016, p. 412), "para esse mecanismo funcionar, é necessário que a família e o jovem acreditem que a frequência escolar 
no presente signifique de fato uma preparação para um futuro melhor." Essa crença parece indicar que há uma internalização de uma disciplina necessária para não abandonar a frequência escolar.

Em Polonia e Dessen (2007) também encontramos a importância dos pais no processo de escolarização dos filhos e, de acordo com os autores, o envolvimento familiar na realização das tarefas aumenta a motivação dos alunos bem como o desejo de continuarem os estudos. A integração entre família e escola tem despertado cada vez mais interesse dos pesquisadores ao destacarem implicações positivas dessa integração, principalmente no que diz respeito ao sucesso escolar do aluno. Ainda conforme as autoras, "os laços afetivos formados dentro da família, particularmente entre pais e filhos, podem ser aspectos desencadeadores de um desenvolvimento saudável e de padrões de interação positivos que possibilitam o ajustamento do indivíduo aos diferentes ambientes de que participa" (POLONIA; DESSEN, 2007, p. 24).

Em outro estudo, realizado por Pratta e Santos (2007), os autores destacam que a maneira como os pais foram educados influencia na educação dos filhos, principalmente em relação à participação na vida escolar. Algumas famílias são mais presentes, mesmo não tendo recebido apoio na sua época escolar, outras não participam, justamente pela ausência da participação dos pais. Em nossa pesquisa o que se destacou é a participação dos pais na vida escolar dos filhos. Esses dados apareceram igualmente no trabalho realizado por Polonia e Dessen (2005). Os autores acreditam que os pais estão procurando desempenhar seu papel na educação dos filhos, mesmo não sabendo exatamente qual caminho seguir para melhor auxiliar os jovens, conforme podemos identificar no posicionamento a seguir: "Eu tenho incentivo do meu pai, sou muito ruim em matemática e meu pai tenta me ajudar, ele tenta me explicar, mas não entra na minha cabeça. Porque quando ele estudava ninguém ajudava ele, por isso quer me dar aquilo que não teve dos meus avós" (H. N. R., 16 anos).

Interessa-nos destacar, ainda, a importância da relação família-escola, mas concordamos com Zago (2012, p. 62) a respeito da necessidade de questionar o forte apelo que tem se direcionado às famílias sobre sua responsabilização no processo de ensino-aprendizagem dos alunos. A autora questiona: "Na sua base, tal intervenção não representa, igualmente, a repetição de práticas de transferência de responsabilidade da educação para as famílias?" Também, segundo a autora, quando se fala em parceria entre família e escola e convocam-se os pais para participarem na educação dos filhos como estratégia para o sucesso escolar, "não se consideram as relações de poder, de classe, raça/etnia, gênero e idade, a diversidade de arranjos familiares e as desvantagens materiais e culturais de uma parte considerável das famílias, que estruturam as relações e a divisão de trabalho em casa e na escola" (ZAGO, 2012, p. 62).

Outro fator destacado pelos jovens como um motivo de permanecerem na escola é em relação aos bons professores, àqueles que sabem dar boas aulas, as quais possibilitam a aprendizagem e, sobretudo, aos professores que demonstram afetividade: "Tive uma professora que no primeiro dia de aula pediu para que escrevêssemos um texto falando sobre nós. Ela demonstrou interesse em nos conhecer, em saber mais sobre nossas vidas" (M. B., 15 anos). O que, porém, é ser bom professor para os jovens? De acordo com as manifestações dos alunos no grupo focal, "o bom professor gosta do 
que faz; explica os conteúdos com clareza e explica mais de uma vez quando precisar; considera a participação dos alunos na aula e, ao mesmo tempo, é exigente; reconhece as dificuldades dos alunos sem culpabilizá-los; é inovador; estabelece relações afetivas com os alunos, respeitando-os; é amigo; é afetivo; se importa" (M. B., 15 anos; A. L., 16 anos; A. M., 14 anos; H. N. R., 16 anos).

Concordamos com Freire (2015), quando afirma que a docência é da ordem da delicadeza tanto quanto ela é da ordem do humano, pois envolve o cuidar. Para Teixeira (2007, p. 433),

[...] a docência diz respeito ao delicado envolvimento, ao delicado comprometimento, a uma delicada preocupação e zelo com os destinos e temporalidades humanos: uma delicadeza para com a vida humana, de todos e todas as mulheres e homens - para com o bem comum. E uma delicadeza para com cada vida, presente em cada um e cada uma, individualmente.

Estabelecer relações afetivas com os alunos é destacado pelos jovens pesquisados como um dos passos mais importantes a ser considerado pelos professores, para que as aulas sejam produtivas e interessantes, vinculado com a vontade de quererem continuar os estudos. Para os alunos, sentirem-se à vontade com o professor e sentirem-se queridos por ele, facilita seu engajamento com as aulas: "Eu gosto dos professores que são nossos amigos, que nos entendem" (B. M., 14 anos).

Na pesquisa desenvolvida por Abramovay, a frequência e a permanência escolar também apareceram atreladas a ter bons professores. O tema "professor" suscitou diferentes pontos de vista. "No entanto, para os jovens, ele é uma figura especial, tanto pela importância de poder contar com competência pedagógica, quanto pelas possíveis relações de afeto e reconhecimento de identidades" (ABRAMOVAY, 2015, p. 235).

Para Freire (2015, p. 90), "o clima de respeito que nasce de relações justas, sérias, humildes, generosas, em que a autoridade docente e as liberdades dos alunos se assumem eticamente, autentica o caráter formador do espaço pedagógico." Cabe demarcar que ensinar é trocar conhecimento, é contribuir para a ressignificação dos conhecimentos dos alunos e, sobretudo, ensinar é possibilitar que os educandos cresçam como pessoas autônomas e éticas para que possam assumir a responsabilidade de suas ações no mundo.

\section{ALGUMAS CONSIDERAÇÕES}

Na pesquisa realizada os jovens destacaram entre os principais motivos para permanecerem na escola o incentivo dos pais, terem bons professores e, sobretudo, para ter uma vida melhor, que está associada a ter um bom emprego. Continuar os estudos é, para eles, um modo de atravessar a fronteira social e econômica. Nesse caso, os alunos destacaram o ter em relação ao ser, posto que estamos cercados por uma sociedade de consumidores. A partir desses resultados, é importante refletir sobre o papel da educação, principalmente das instituições escolares, em auxiliar os jovens a refletirem sobre o sentido do ter, para que possam ressignificar a importância do ser. 
Além disso, os depoimentos apresentados no decorrer da pesquisa desafiam uma crença fortemente arraigada pelo senso comum: a de que os jovens (especialmente os pertencentes às camadas populares) possuem famílias desestruturadas, que não incentivam os estudos e, ainda, que os jovens não têm vontade de estudar. Este trabalho evidencia o contrário; mostra o interesse dos jovens pelos estudos e, ainda, destaca a importância de os professores se prepararem para as aulas, se importarem e os considerarem seres partícipes das aulas, tendo o incentivo dos pais como um reforço positivo para continuarem os estudos.

Os dados da pesquisa, juntamente com outros dados de investigações assinaladas neste artigo, podem constituir referencial em relação à compreensão do que os alunos pensam e do valor atribuído à escola, ao ambiente escolar, aos estudos e à perspectiva de futuro. Verificamos que os motivos que se vinculam à permanência dos jovens na escola são de diferentes naturezas, tanto os escolares quanto os extraescolares. Os profissionais que atuam na escola necessitam construir instrumentos e espaços de verbalização e de escuta para que os alunos explicitem sua compreensão a respeito de sua concordância ou não do que acontece na escola, e que esses dados de diagnóstico possam "mover" ações de planejamento e de mudanças no encaminhamento de situações do cotidiano que não contribuem para o alcance dos objetivos da instituição escolar. Ainda que não tenhamos a pretensão de tornar os depoimentos dos jovens verdades absolutas, compreendemos que não podemos desconsiderar o que eles têm a falar sobre aquilo que vivenciam no cotidiano escolar.

\section{REFERÊNCIAS}

ABRAMOVAY, Miriam; CASTRO, Mary Garcia. Ensino Médio: múltiplas vozes. Brasília, DF: Unesco; MEC, 2003.

ABRAMOVAY, Miriam. Juventudes na escola, sentidos e buscas: por que frequentam? Brasília, DF: Flacso-Brasil; OEI; MEC, 2015.

ARROYO, Miguel G. O humano é viável? É educável? Revista Pedagógica, Chapecó, v. 17, p. 21-40, 2015.

BAUMAN, Zigmunt. Modernidade líquida. Rio de Janeiro: Zahar, 2001.

BAUMAN, Zigmunt. Sobre educação e juventude: conversas com Riccardo Mazzeo. Rio de Janeiro: Zahar, 2013.

BAUMAN, Zigmunt; LEONCINI, Thomas. Nascidos em tempos líquidos: transformações no terceiro milênio. Rio de Janeiro: Zahar, 2018.

BRASIL. Metodologia do censo demográfico. Rio de Janeiro: IBGE, 2013. 712 p. (Relatórios metodológicos, V. 41).

CAIERÃO, lara. Jovens e escola: trajetórias, sentidos e significados: um estudo em escolas públicas de Ensino Médio. 2008. Tese (Doutorado em Educação) - Universidade Federal do Rio Grande do Sul, Porto Alegre, 2008.

DAYRELL, Juarez Tarcisio; JESUS, Rodrigo Ednilson de. Juventude, Ensino Médio e os processos de exclusão escolar. Educação e Sociedade, Campinas, v. 37, n. 135, p. 407-423, abr./jun. 2016.

DESSEN, Maria Auxiliadora; POLONIA, Ana da Costa. A família e a escola como contextos de desenvolvimento humano. Paidéia, Ribeirão Preto, v. 17, n. 36, p. 21-32, abr. 2007.

FRANCO, Maria Laura Barbosa. As representações sociais de alunos da 8 $^{a}$ série inseridos em oito escolas estaduais do município de São Paulo. Psicologia da Educação, São Paulo, v. 15, n. 14, p. 189-205, 2002.

FRANCO, Maria Laura Barbosa; NOVAES, Gláucia Torres Franco. Os jovens do ensino médio e suas representações sociais. Cadernos de Pesquisa, São Paulo, n. 112, p. 167-183, mar. 2001.

FREIRE, Paulo. Pedagogia da autonomia: saberes necessários à prática educativa. 50. ed. Rio de Janeiro: Paz e Terra, 2015. 
GOMES, Claudia; SOUZA, Vera Lucia Trevisan de. Fracassos, representações e exclusões no processo de permanência na escola. Revista Psicopedagia, São Paulo, v. 26, n. 79, p. 41-47, 2009.

INEP. Instituto Nacional de Estudos e Pesquisas Educacionais Anísio Teixeira. Dados preliminares do Censo da Educação Escolar. Brasília, DF: Inep, 2017. Disponível em: www.inep.com.br. Acesso em: 2 maio 2019. MELO, Luciano Plez de; SALLES, Leila Maria Ferreira. Escola, juventude e perspectivas de futuro: alguns apontamentos. Cadernos Cedes, Campinas, v. 40, n. 110, p. 86-96, mar. 2020.

MEYER, Dagmar Estermann; PARAÍSO, Marlucy Alves. Metodologias de pesquisas pós-críticas em educação. 2. ed. Belo Horizonte: Mazza, 2014.

MORAES, Roque; GALIAZZI, Maria do Carmo. Análise textual discursiva. 3. ed. rev. e ampl. ljuí: Editora Unijuí, 2016.

NOGARO, Arnaldo; PACHECO, Luci Mary Duso. Práticas pedagógicas e relações humanas na sociedade líquida a partir da metáfora do jardineiro e do caçador. In: FAVERO, Altair; TONIETO, Carina; CONSALTER, Evandro. Leituras sobre Bauman e a educação. Curitiba: Ed. CRV, 2019. p. 121-138.

NOVAES, Regina. Os jovens e hoje: contextos, diferenças e trajetórias. In: ALMEIDA, Maria Isabel Mendes de; EUGÊNIO, Fernanda (org.). Culturas jovens: novos mapas do afeto. Rio de Janeiro: Jorge Zahar, 2006. p. 105-121.

NUSSBAUM, Martha. Sem fins lucrativos: por que a democracia precisa das humanidades. São Paulo: Ed. WMF, 2015.

PIAGET, Jean. Para onde vai a educação? 14. ed. Tradução Ivette Braga. Rio de Janeiro: José Olympio, 1998.

POLONIA, Ana da Costa; DESSEN, Maria Auxiliadora. Em busca de uma compreensão das relações entre família escola. Psicologia Escolar e Educacional, Campinas, v. 9, n. 2, p. 303-312, dez. 2005.

PORCHEDDU, Alba. Zygmunt Bauman: entrevista sobre a educação. Desafios pedagógicos e modernidade líquida. Cadernos de Pesquisa, São Paulo, v. 39, n. 137, p. 661-684, ago. 2009.

PRATTA, Elisângela Maria Machado; SANTOS, Manoel Antonio dos. Família e adolescência: a influência do contexto familiar no desenvolvimento psicológico de seus membros. Psicologia e Estudos, Maringá, v. 12, n. 2, p. 247-256, ago. 2007.

SOUZA, Marilene Proença. A queixa escolar e o predomínio de uma visão de mundo. In: MACHADO, Adriana; SOUZA, Marilene Proença (org.). Psicologia escolar: em busca de novos rumos. São Paulo: Casa do Psicólogo, 1997. p. 17-33.

TEIXEIRA, Inês Assunção de Castro. Da condição docente: primeiras aproximações teóricas. Educação $e$ Sociedade, Campinas, v. 28, n. 99, p. 426-446, maio/ago. 2007.

TESSARO, Mônica. Jovens olhares sobre a escola: vivências dos processos educativos a partir do background e do forenground. 2018. Dissertação (Mestrado em Educação) -Universidade Comunitária da Região de Chapecó, Chapecó, 2018.

VELHO, Gilberto. Juventudes, projetos e trajetórias na sociedade contemporânea. In: ALMEIDA, Maria. Isabel Mendes; EUGENIO, Fernanda (org.). Culturas jovens: novos mapas do afeto. Rio de Janeiro: Jorge Zahar, 2006. p. 192-202.

ZAGO, Nadir. Fracasso e sucesso escolar no contexto das relações família-escola: tendências de pesquisa em Sociologia da Educação. Sociologia da Educação - Revista Luso-Brasileira, v. 1, p. 57-83, mar. 2012. 